\title{
Medical undergraduate palliative care education (UPCE)
}

\begin{abstract}
${ }^{1}$ Academic Department of Palliative Medicine, Our Lady's Hospice and Care Services, Dublin, Ireland

${ }^{2}$ Palliative Medicine, Oxford University Hospitals NHS Trust, Oxford, UK
\end{abstract}

\section{Correspondence to}

Dr Des McMahon, Academic Department of Palliative

Medicine, Our Lady's Hospice and Care Services, Dublin D6W RY72, Ireland;

mcmahon_des@yahoo.ie

Received 12 July 2019 Accepted 17 July 2019

\section{Check for updates}

(C) Author(s) (or their employer(s)) 2019. No commercial re-use. See rights and permissions. Published by BMJ.

To cite: McMahon D, Wee B. BMJ Supportive \& Palliative Care Epub ahead of print: [please include Day Month Year]. doi:10.1136/ bmjspcare-2019-001965

\section{Des McMahon, ${ }^{\circ}$ Bee Wee ${ }^{2}$}

\section{INTRODUCTION}

As interns, new doctors care for the dying or others who have palliative care (PC) needs. ${ }^{1}$ Undergraduate medical students need to learn about PC. ${ }^{2}$ Up to half of newly qualified doctors are underprepared for end of life issues and many feel it is a source of distress. ${ }^{34}$ Medical students value palliative education ${ }^{5}$ but many feel training is deficient. ${ }^{67}$

Undergraduate palliative care education (UPCE) for medical students shows wide variation throughout Europe and internationally. ${ }^{8}$ In 2015, PC was compulsory in only $14 \%$ of countries; only $30 \%$ of European medical schools taught PC. ${ }^{9}$ Medical curricula did not include PC in 14 countries (33\%).

In the UK, the General Medical Council requires that newly qualified doctors: 'Contribute to the care of patients and their families at the end of life, including management of symptoms, practical issues of law and certification, and effective communication and team working.' 10

Current UPCE-related literature gives guidance on effective delivery of PC education for medical students (box 1).

\section{RECOMMENDATIONS}

UPCE should be mandatory and based on a nationally agreed curriculum

In the past, UPCE was often voluntary. Students recommended a course for all

\section{Box 1}

Palliative care education for medical students should:

- Be mandatory and based on a nationally agreed curriculum.

- Be introduced early and integrated in the wider curriculum.

- Involve clinical exposure.

- Include objective assessment.

- Be delivered by a multidisciplinary team.

- Be competence based. undergraduates as a medical curriculum core component. ${ }^{11}$ They agreed PC training is essential. ${ }^{12}$

Optional PC teaching suggests PC is unimportant ${ }^{13}$ and is a barrier to discipline development. ${ }^{9}$ PC teaching improves PC attitudes. ${ }^{14}$ Australia, Canada and the UK have adopted nationally agreed curricula which reduces the degree of variation in the UPCE delivery. ${ }^{3} 15$

\section{UPCE should be introduced early and integrated in the wider curriculum}

Undergraduate education needs to create an environment in which students develop the attitudes, knowledge and skills necessary for compassionate and effective PC. ${ }^{2}$ Direct exposure should occur early in medical school curricula. ${ }^{16}$ It is important to teach attitudinal concepts. ${ }^{17}$ Junior doctors with early PC training have enhanced communication, patient-centred medicine, professionalism, self-awareness skills and teamwork. ${ }^{18}$

UPCE is no longer a stand-alone subject and integration into undergraduate medical curricula is important. ${ }^{17}$ PC should be included in cardiology, neurology, nephrology, oncology and respiratory medicine (horizontal integration), and throughout undergraduate education (vertical integration). Training must include recognising and addressing PC needs in practice.

\section{UPCE should involve clinical exposure}

Despite resource challenges, an educationally rich PC curriculum should include both didactic elements and clinical experience. ${ }^{19}$ This provides compassionate and competent PC role modelling and supervised experience. Clinical experience exposure during undergraduate clinical years increases significant learning. ${ }^{19}$ Students regard PC teaching as important and essential. ${ }^{11}$ In the UK, increased medical student time includes time with hospice patients. ${ }^{20}$ 


\section{UPCE should involve objective assessment}

PC assessment involves more than self-assessment. ${ }^{13}$ Objective assessments are increasingly used rather than self-report of satisfaction or perceived skill level. ${ }^{7}$ Medical education typically focuses on knowledge and skills but attitudinal aspects are equally important. PC spans many medical specialties and evaluation should be longitudinal. ${ }^{21}$

\section{UPCE should be delivered by a multidisciplinary team}

Traditionally, physicians teach medicine but an interprofessional team delivers patient care. ${ }^{22}$ Interprofessional PC education is a rewarding professional experience $^{22}$ and an educational design strength. ${ }^{21}$

\section{UPCE should be competence based}

The medical education challenge is to increase and apply knowledge that will be reflected in clinical performance and enhanced patient care. ${ }^{19}$ The European Association for Palliative Care has advocated such training to promote leadership and enlightened change. ${ }^{23} \mathrm{~A}$ curriculum should achieve requisite competencies. Such competencies should encompass behaviour and attitudes, as well as knowledge and skills. ${ }^{24}$ Competence-based questionnaires and assessments which reliably examine knowledge, behaviour and attitudes are being developed. ${ }^{24}$

\section{CHALLENGES}

These recommendations are to equip future doctors with complex medical and psychosocial skills for life-limiting illness. However, they pose significant challenges. There are resource and curriculum time pressures in busy medical undergraduate curricula. ${ }^{25}$ Current medical school curricula are already overstrained. ${ }^{5}$ In addition, there are concerns about insufficient funding, placements and teachers. ${ }^{15}$ More innovative teaching methods, including online teaching and actors as simulated patients, help overcome resource limitations. ${ }^{26}$ New teaching and evaluation methods, including online and virtual, help in environments with limited clinical access. ${ }^{27}$ eLearning is promising and well accepted by medical students but as a supplement rather than substitute. ${ }^{28}$

\section{CONCLUSIONS}

Appropriate training is essential for PC safe practice. $^{7}$ PC undergraduate education increases confidence and control to interact with dying patients and families. ${ }^{18}$ Learning the PC approach helps address terminal illness and general patient care. ${ }^{18}$ Palliative medicine academic departments play a key role in supporting and strengthening undergraduate PC teaching and learning. ${ }^{29}$

Contributors DM carried out the relevant literature review and wrote the first draft of this article. BW provided a substantial contribution to the design of the work and to revising it critically for important intellectual content. Both authors agree to be accountable for all aspects of the work in ensuring that questions related to the accuracy or integrity of any part of the work are appropriately investigated and resolved.

Funding The authors have not declared a specific grant for this research from any funding agency in the public, commercial or not-for-profit sectors.

Competing interests None declared.

Patient consent for publication Not required.

Provenance and peer review Not commissioned; internally peer reviewed.

\section{REFERENCES}

1 Gibbins J, McCoubrie R, Maher J, et al. Recognizing that it is part and parcel of what they do: teaching palliative care to medical students in the UK. Palliat Med 2010;24:299-305.

2 European Association for Palliative Care. Curriculum in palliative care for undergraduate medical education, 2007. Available: www.eapcnet.eu/LinkClick.aspx? fileticket $=$ VmnUSgQm5PQ\%3D

3 Fitzpatrick D, Heah R, Patten S, et al. Palliative care in undergraduate medical Education-How far have we come? Am J Hosp Palliat Care 2017;34:762-73.

4 Bharmal A, Morgan T, Barclay S. 48 Junior doctors and end of life care: a systematic review and narrative synthesis. BMJ Support Palliat Care 2018;8:378.1-378.

5 Horowitz R, Gramling R, Quill T. Palliative care education in US medical schools. Med Educ 2014;48:59-66.

6 Chiu N, Cheon P, Lutz S, et al. Inadequacy of palliative training in the medical school curriculum. J Canc Educ 2015;30:749-53.

7 Walker S, Gishen F, Lodge P, et al. Teaching palliative care (PC) to medical students; are we developing safe practitioners? BMJ Support Palliat Care 2015;5:106.1-106.

8 EAPC Steering Group on Medical Education and Training in Palliative Care. Recommendations of the European association for palliative care (EAPC) for the development of undergraduate curricula in palliative medicine at European medical schools, 2013. Available: http://www.eapcnet.eu/ LinkClick.aspx? fileticket=S1MI-tuIutQ\%3D [Accessed 19 Jan 2018].

9 Carrasco JM, Lynch TJ, Garralda E, et al. Palliative care medical education in European universities: a descriptive study and numerical scoring system proposal for assessing educational development. J Pain Symptom Manage 2015;50:516-23.

10 GMC. Outcomes for graduates, 2015. Available: https:// www.gmc-uk.org/static/documents/content/Outcomes_for_ graduates_Dec_16.pdf [Accessed 19 Jan 2018].

11 Centeno $\bar{C}$, Ballesteros M, Carrasco JM, et al. Does palliative care education matter to medical students? the experience of attending an undergraduate course in palliative care. BMJ Support Palliat Care 2016;6:128-34.

12 Parikh PP, White MT, Buckingham L, et al. Evaluation of palliative care training and skills retention by medical students. J Surg Res 2017;211:172-7.

13 Head BA, Schapmire TJ, Earnshaw L, et al. Improving medical graduates' training in palliative care: advancing education and practice. Adv Med Educ Pract 2016;7:99-113.

14 Brand AH, Harrison A, Kumar K. "It Was Definitely Very Different": An evaluation of palliative care teaching to medical students using a mixed methods approach. J Palliat Care 2015;31:21-8.

15 Lawrie I, Walker S. P-111 palliative care training for nonspecialists: what happens in UK medical schools, primary care and hospital practice? how might deficits be addressed? 2017. Available: http://spcare.bmj.com/content/7/Suppl_1/A41.2. abstract [Accessed 17 Jan 2018]. 
16 Wechter E, O'Gorman DC, Singh MK, et al. The effects of an early observational experience on medical students' attitudes toward end-of-life care. Am J Hosp Palliat Care 2015;32:52-60.

17 MacPherson A, Lawrie I, Collins S, et al. Teaching the difficultto-teach topics. BMJ Support Palliat Care 2014;4:87-91.

18 Crawford GB, Zambrano SC. Junior doctors' views of how their undergraduate clinical electives in palliative care influenced their current practice of medicine. Acad Med 2015;90:338-44.

19 Sanchez-Reilly S, Ross JS. Hospice and palliative medicine: curriculum evaluation and learner assessment in medical education. J Palliat Med 2012;15:116-22.

20 Dickinson GE, Paul ES. End-Of-Life issues in UK medical schools. Am J Hosp Palliat Care 2015;32:634-40.

21 DeCoste-Lopez J, Madhok J, Harman S. Curricular innovations for medical students in palliative and end-of-life care: a systematic review and assessment of study quality. $J$ Palliat Med 2015;18:338-49.

22 Gadoud A, Lu W-H, Strano-Paul L, et al. A pilot study of interprofessional palliative care education of medical students in the UK and USA. BMJ Support Palliat Care 2018;8.

23 Gamondi C, Larkin P, Payne S. Core competencies in palliative care: An EAPC white paper on palliative care education - Part 1. Eur J Palliat Care 2013;20:86-91.
24 Connolly M, McLean S, Guerin S, et al. Development and initial psychometric properties of a questionnaire to assess competence in palliative care: palliative care competence framework questionnaire. Am J Hosp Palliat Care 2018;35:1304-8.

25 Linklater GT, Bowden J, Pope L, et al. Developing learning outcomes for medical students and Foundation doctors in palliative care: a national consensus-seeking initiative in Scotland. Med Teach 2014;36:441-6.

26 Romotzky V, Galushko M, Düsterdiek A, et al. "It's Not that Easy"-Medical Students' Fears and Barriers in End-of-Life Communication. J Canc Educ 2015;30:333-9.

27 Tan A, Ross SP, Duerksen K. Death is not always a failure: outcomes from implementing an online virtual patient clinical case in palliative care for family medicine clerkship. Med Educ Online 2013;18:22711.

28 Schulz-Quach C, Wenzel-Meyburg U, Fetz K. Can elearning be used to teach palliative care? - medical students' acceptance, knowledge, and self-estimation of competence in palliative care after elearning. BMC Med Educ 2018;18:82.

29 Walker S, Gibbins J, Paes P, et al. Palliative care education for medical students: differences in course evolution, organisation, evaluation and funding: a survey of all UK medical schools. Palliat Med 2017;31:575-81. 